Article

\title{
Impact of Out-of-Pocket Cost on Herpes Zoster Vaccine Uptake: An Observational Study in a Medicare Managed Care Population
}

\author{
Zhuliang Tao ${ }^{1}$, Yong Li ${ }^{1}$, Stephen Stemkowski ${ }^{1, *}$, Kelly D. Johnson ${ }^{2}$, Camilo J. Acosta ${ }^{3}$, \\ Dongmu Zhang ${ }^{2}$ and A. Mark Fendrick ${ }^{4}$ \\ 1 Comprehensive Health Insights, Inc., a Humana Co., 515 West Market Street Louisville, KY 40202, USA; \\ zhuliangtao@gmail.com (Z.T.); yli4@humana.com (Y.L.) \\ 2 Merck and Co., Inc. Center for Observational \& Real World Evidence, 2000 Galloping Hill Rd, \\ Kenilworth, NJ 07033, USA; kelly.johnson@merck.com (K.D.J.); zhangdongmu@hotmail.com (D.Z.) \\ 3 Merck Research Laboratories, 2000 Galloping Hill Rd, Kenilworth, NJ 07033, USA; \\ camilo_acosta2003@yahoo.com \\ 4 Center for Value-Based Insurance Design, North Campus Research Complex, 2800 Plymouth Road, \\ Building 16/Floor 4/Room 455S, Ann Arbor, MI 48109-2800, USA; amfen@umich.edu \\ * Correspondence: sstemkowski@humana.com; Tel.: +1-502-307-2751
}

Received: 4 June 2018; Accepted: 16 November 2018; Published: 21 November 2018

\begin{abstract}
Herpes zoster (HZ) vaccination is approved for adults aged 50+ for the prevention of $\mathrm{HZ}$, but it is underutilized. The objective of this study was to evaluate the association between out-of-pocket cost and $\mathrm{HZ}$ vaccine utilization. Adults aged 65 or older enrolled for at least 12 months in Medicare Advantage/Part D (MAPD) and Medicare Part D only (PDP) plans from 1 January 2007 to 30 June 2014 were selected. Abandonment was defined as a reversed claim for $\mathrm{HZ}$ vaccine with no other paid claim within 90 days. Out-of-pocket costs used were actual amounts recorded in the claim. Overall, the $\mathrm{HZ}$ vaccine abandonment rate was $7.3 \%$. Mean out-of-pocket costs were higher for individuals who abandoned versus those who did not (\$88 ( $\pm \$ 55)$ versus $\$ 80( \pm \$ 49)$ ). Logistic regression indicated individuals with out-of-pocket costs of $\$ 80-\$ 90$ were $21 \%$ more likely $(\mathrm{OR}=1.21$, $1.16-1.2795 \% \mathrm{CI}$ ), and those with out-of-pocket costs $>\$ 90$ were $90 \%$ more likely (OR $=1.90,1.85-1.96$ $95 \%$ CI) to abandon than those with out-of-pocket costs $<\$ 80$. The models also suggested that socioeconomic, racial, and ethnic disparities in vaccine abandonment existed. Different vaccine targeting efforts and pharmacy benefit design strategies may be needed to increase use, improve adherence, and minimize disparities.
\end{abstract}

Keywords: out-of-pocket costs; herpes zoster vaccine; vaccination rate; utilization; abandonment

\section{Introduction}

Herpes zoster (HZ), which is also known as shingles or zoster, is a manifestation of the reactivation of the varicella-zoster virus (VZV), which induces chickenpox as a primary infection. Following the initial VZV infection, the virus remains latent in sensory ganglia. In some individuals, latent VZV reactivates and replicates, perhaps as a consequence of waning cellular immunity, resulting in HZ [1-8]. Herpes zoster is a common disease with an overall annual incidence rate estimated at 4.5/1000 person-years in the United States (US) and ranging up to nearly 12.8/1000 person-years in adults aged 60 years and older [9]. As incidence increases with age, $\mathrm{HZ}$ and its complications are seen mostly in aged populations and may cause substantial acute and chronic morbidity $[10,11]$. The most common long-term complication of $\mathrm{HZ}$ is persistent pain, which is known as postherpetic neuralgia, which can persist for several months to years and may severely affect a patient's quality of life [10]. 
Treatment options are available for patients with postherpetic neuralgia; however, the results of these treatments are limited. Prevention by immunization as recommended by the Centers for Disease Control and Prevention (CDC) might be viewed as potentially more effective and also more appealing to patients $[12,13]$.

The single-dose, live $\mathrm{HZ}$ vaccine has been shown to be safe and effective, as demonstrated by Oxman et al. [14]. This large double-blind, placebo-controlled randomized trial with 38,546 immunocompetent persons 60 years of age and older showed that a single vaccination against $\mathrm{HZ}$ markedly reduced the incidence of HZ (5.42/1000 person-years in the vaccine group, versus 11.12 per 1000 person-years in the placebo group; an absolute difference of 5.70/1000 person-years). The vaccine also decreased the burden of illness due to $\mathrm{HZ}$ by $61 \%$ and the incidence of postherpetic neuralgia by $67 \%$ [14]. These and other such results have led to the $\mathrm{HZ}$ vaccine being recommended by the Advisory Committee on Immunization Practices (ACIP), which is a panel of medical and public health experts that develops vaccination strategies for public health. The ACIP recommendation advises a single dose of the vaccine for immunocompetent adults aged 60 years or older, regardless of whether or not they report a prior episode of herpes zoster [15]. While the live herpes zoster vaccine is no longer considered first-line treatment, it is still a recommended intervention. Although the U.S. Food and Drug Administration (FDA) approved the vaccine for use among persons aged 50 years and older without contraindications, the ACIP recommends vaccinations begin at the age of 60 . According to recent estimates, only $24 \%$ of all adults aged 60 years or older received the vaccine, which is a level that falls well short of the Healthy People $2020 \mathrm{HZ}$ vaccination goal of $30 \%$ [16].

The reasons for low $\mathrm{HZ}$ vaccination rates are thought to include, but are not limited to, financial barriers, lack of awareness, copay structure, lack of routine stocking of the vaccine, and one's unwillingness to comply with the doctor's advice [17]. Hurley et al. found that among internists and family medicine physicians, the most frequently reported barriers to vaccination were financial. Strikingly, only $45 \%$ of physicians knew that the HZ vaccine is reimbursed through Medicare Part D; and, of those who were receiving reimbursements, roughly $12 \%$ stopped administering the vaccine because of cost and reimbursement issues [17].

Information is lacking on the relationship between cost-sharing and use of the vaccine by beneficiaries with Medicare coverage. Since low vaccine adoption undermines public health efforts aimed at reducing the burden of herpes zoster, we examined the factors associated with HZ vaccine use among individuals enrolled in Medicare Advantage/Part D (MAPD) and Part D only (PDP) plans.

\section{Materials and Methods}

\subsection{Data Source}

Individuals aged 65 or older, as well as certain younger people with disabilities, are eligible for the Medicare program in the United States. Medicare Advantage (MA) plans are health plans that are approved by Medicare, and offered and administered by private insurers. These plans are required by law to cover all hospital and physician services that the original Medicare plan covers. Many MA plans also include prescription drug coverage, i.e., MAPD. Stand-alone prescription drug plans (PDP), are also available. Humana is the one of the largest providers of MAPD and PDP plans in the United States. This retrospective observational cohort study used data collected from Humana, Inc. (Louisville, KY, USA) health plan claims for the period 1 January 2007 through 30 June 2014. The data sources for this study included member enrollment, medical, and pharmacy claims data and health plan benefit design data that were linked to each member via a unique patient identifier, plan benefit package code, and formulary identifier. Socioeconomic and additional demographic data were obtained from AmeriLINK ${ }^{\circledR}$ market data, licensed by Humana, and matched to the research data at the member level by a third party using a unique, randomly generated member identifier under the appropriate protective agreements necessary to confirm a positive link. The study protocol and relevant supporting information were approved by Schulman and Associates, which is an independent 
Institutional Review Board (Protocol No. 0000343). The process for de-identifying datasets complied with the de-identification standard in the HIPAA privacy rule, as outlined in CFR 164.514.

\subsection{Selection of Subjects}

Individuals enrolled in a Medicare Advantage/Part D (MAPD) or Medicare Part D only (PDP) health plan, and aged 65 or older who were eligible for the herpes zoster vaccine based on indicated age between 1 January 2007 and 30 June 2014 were identified for study inclusion. Though the vaccine is indicated for adults aged 60 years or older, vaccine coverage for adults aged 60-64 is addressed differently from Part D requirements regarding the elements of vaccine administration and cost-sharing considerations.

The study period encompassed 1 January 2007 through 30 June 2014. The identification period was 1 April 2007 through 30 June 2013. Individuals who had any pharmacy claims for the zoster vaccine were selected, and the first observed date for the vaccine recorded was designated as the index date. A 90-day pre-index period and a 365-day post-index period were established for the analysis. Members with pharmacy coverage but no prescription drug utilization history, members with dual eligibility for Medicare and Medicaid, low-income subsidy recipients, and members with evidence of receiving the $\mathrm{HZ}$ vaccine prior to age 65 were excluded from the study. Members aged 90 or older at index were excluded from all of the analyses.

\subsection{Primary Study Measures}

Vaccine use was identified by National Drug Code and Generic Product Identifier (GPI) codes. Vaccine abandonment was a dichotomous variable indicating whether or not the individual fulfilled the vaccine prescribed by their physician. An individual was considered to have abandoned the vaccine when a claim record indicated that a HZ vaccine order was never fulfilled or had been reversed, and no other paid record of the vaccine was observed in the 90-day period following the non-fulfillment of the index vaccination. Vaccine abandonment rates were calculated as the ratio of the number of people who abandoned their $\mathrm{HZ}$ vaccine to the number of people who had a claim for the vaccine. Rates were calculated using both electronically-transmitted and traditionally processed pharmacy claims, i.e., paper claims.

Member out-of-pocket amounts were the actual member OOP cost in the claim record, in US dollars (\$) from the prescription claim in which the HZ vaccine was reported. This value represented the actual amount for which the member was responsible based on the accrued applicable deductibles and copayment requirements in place at the time the claim was incurred. We capped the maximum OOP amount at the average wholesale price plus $20 \%$ (\$275) to address obvious outlier values (less than $1 \%$ of cases). All of the members were classified into these mutually-exclusive categories of OOP expense amounts reported in the claim: $\$ 0-\$ 80,>\$ 80-<\$ 90$, and $\$ 90$ or more to reflect distribution characteristics of the OOP amounts.

\subsection{Other Relevant Measures}

Other measures of interest included demographic and clinical characteristics during the pre-index period. Age at index, gender, and geographic region were determined from enrollment data. Race was available in the Center for Medicare and Medicaid Service's (CMS) enrollment data for patients with Medicare coverage. Region was based on the state of residence, grouped into regions according to census classifications. To determine community type, we divided the population into three categories: rural, urban, and suburban. Population density was assigned to a community type class by matching member zip codes to Rural-Urban Commuting Area (RUCA) codes and applying the Washington State Department of Health's RUCA consolidation system as follows: (1) Urban (50,000 persons or more); (2) Suburban (small cities/large towns); (3) Rural (small towns with populations below 10,000 or isolated rural areas). 
Estimated household income was derived from financial survey data at the person level by AmeriLINK $^{\circledR}$. Education levels were also provided by AmeriLINK ${ }^{\circledR}$ based on self-reported responses and 2010 census data. Comorbidity burden was measured by the RxRisk-V score, which is a prescription claims-based comorbidity index originally developed for use in the Veterans Health Administration (VHA) population [18]. The score was determined based on the identification of 45 distinct comorbid conditions via their associated medication treatments. To calculate the RxRisk-V score, comorbid conditions were mapped to drug classes and individual drugs via Medi-Span GPI codes. By construction, the RxRisk-V score can range from 0 to 45 , with a higher score indicating a greater number of comorbid conditions.

\subsection{Statistical Analysis}

The study examined HZ vaccine adoption by assessing the extent of vaccine abandonment among those who received prescriptions for it. Descriptive analyses of vaccine use were conducted to estimate the overall abandonment rate. Results were stratified and reported by member OOP cost categories. The multivariable abandonment analyses used odds ratio estimates and 95\% confidence intervals from logistic regression models to identify key factors related to vaccine non-compliance. The outcome variable of the logistic models was the likelihood of abandoning a HZ vaccine order. Factors related to household income, educational attainment, coverage type, gender, age, regional differences, and patient share of the cost of the vaccine were described and introduced into multivariable models to estimate the impact of these factors. Community type (rural, suburban, or urban), Medicare plan type, and RxRisk-V score were included in the analysis as covariates. Covariates were evaluated for collinearity before entering into the models. Model fit was assessed via C statistic.

\section{Results}

Overall, 6,295,970 individuals met the selection criteria and were included in the analysis. Of these, 2,547,652 (40.5\%) were enrolled in MAPD, and 3748.318 (59.5\%) were enrolled in PDP. Females comprised $59.0 \%$ of the sample overall, which was a pattern that was reflected in the MAPD and PDP cohorts individually (Table 1). Mean age was reported at $72.6( \pm 6.1$, standard deviation) years and $73.4( \pm 6.6)$ years in the MAPD and PDP cohorts, respectively. Individuals from the Midwest and south comprised $85 \%$ of the MAPD cohort, but only $65 \%$ of the PDP sample. Nearly two-thirds of the sample were in households with less than $\$ 45,000$ annual household income. Half reported at least some college education. The mean RxRisk-V comorbidity index was similar for MAPD (5.10 \pm 2.86$)$ and PDP (5.02 \pm 2.95$)$ members.

With regard to vaccine abandonment rates, we found that for those individuals with a claim for the HZ vaccine, ( $n=192,606,35 \%$ MAPD, $n=357,623,65 \%$ PDP, Table 2$), 8.9 \%$ of MAPD and $6.4 \%$ of PDP members did not fulfill the vaccine. This represents an overall abandonment rate for the vaccine of 7.3\% for Medicare members. Interestingly, members in PDP plans, despite higher OOP amounts, reported fewer abandoned $\mathrm{HZ}$ vaccine prescriptions than did members in MAPD. The mean OOP cost for members in MAPD plans who abandoned the vaccine was $\$ 79.76$ ( $\pm \$ 45.51$ ) compared with $\$ 71.35$ ( \pm \$40.95) for members who did not. Similarly, mean OOP amounts for PDP members who did not fulfill the vaccine order was $\$ 94.52$ ( \pm \$61.08) versus $\$ 84.83$ ( $\pm \$ 52.17$ ) for members who did.

Three multivariable analyses were conducted (MAPD, PDP, and combined) to understand the key factors related to the likelihood of a patient to abandon the HZ vaccine. Overall, and by Medicare plan type, female members had a 4-7\% lower odds of abandoning the HZ vaccine than male members. Increasing age also was significantly associated with abandonment. Black and Hispanic members were found by all three models to be more likely than white members to abandon the vaccine.

Relative to those in the northeast, individuals in the south had $40 \%$ higher odds, and individuals in the Midwest $11 \%$ lower odds, of abandoning the HZ vaccine. Compared to suburban members, urban members were more likely, while rural members were less likely, to abandon (Table 3). 
We observed an inverse relationship between the likelihood of vaccine abandonment and educational attainment level. Individuals with a high school diploma had 16\% higher odds, and those with less than a HS diploma had 33\% higher odds of abandoning the vaccine than individuals with at least some college education. Similarly, individuals with household incomes between $\$ 45,000$ and $\$ 87,000$ had $23 \%$ higher odds of abandoning than those whose income was greater than $\$ 87,000$. Individuals whose incomes were less than $\$ 45,000$ had nearly 50\% higher odds of abandonment. Individuals with a higher comorbidity index also were more likely to abandon (Table 3).

Compared to those with an OOP amount less than $\$ 80$, the odds of abandonment was $21 \%$ higher among individuals whose OOP amount was between \$80-90, and 90\% higher among individuals whose OOP amount was greater than \$90. Putting this in perspective, among individuals with an OOP amount less than $\$ 80$, about $6.9 \%$ did not fulfill their $\mathrm{HZ}$ vaccine order, giving estimated odds of 0.074. Based on the logit models, an OOP amount between \$80-90 would increase the odds of abandonment to 0.090 , and an OOP amount greater than $\$ 90$ would increase the odds of abandonment to 0.141 . Despite the relatively higher OOP amounts, members enrolled in PDP had 16\% lower odds of abandoning the $\mathrm{HZ}$ vaccine than did members in MAPD plans. (Table 3).

Table 1. Baseline Demographic Characteristics of Herpes zoster (HZ) Vaccine Eligible Adults by Coverage Type. MAPD: Medicare Advantage/Part D.

\begin{tabular}{|c|c|c|c|c|c|c|}
\hline \multirow{3}{*}{ Eligible Members (Count) } & \multicolumn{2}{|c|}{ Medicare MAPD } & \multicolumn{2}{|c|}{ Medicare Pt D } & \multicolumn{2}{|c|}{ All } \\
\hline & \multicolumn{2}{|c|}{$2,547,652$} & \multicolumn{2}{|c|}{$3,748,318$} & \multicolumn{2}{|c|}{$6,295,970$} \\
\hline & $N$, or Means & $\%$, or SD & $N$, or Means & $\%$, or SD & $N$, or Means & $\%$, or SD \\
\hline \multicolumn{7}{|l|}{ Gender (count, \%) } \\
\hline Female & $1,432,202$ & 56.0 & $2,281,911$ & 61.0 & $3,714,113$ & $59.0 \%$ \\
\hline Male & $1,115,450$ & 44.0 & $1,466,407$ & 39.0 & $2,581,857$ & $41.0 \%$ \\
\hline Age (Mean, SD) & 72.56 & 6.14 & 73.42 & 6.58 & 73 & 6.00 \\
\hline \multicolumn{7}{|c|}{ Geographic Region (count, \%) } \\
\hline Midwest & 601,217 & 24.0 & $1,008,646$ & 27.0 & $1,609,863$ & $25.6 \%$ \\
\hline Northeast & 67,250 & 3.0 & 523,248 & 14.0 & 590,498 & $9.4 \%$ \\
\hline South & $1,565,019$ & 61.0 & $1,417,258$ & 38.0 & $2,982,277$ & $47.4 \%$ \\
\hline West & 296,017 & 12.0 & 777,838 & 21.0 & $1,073,855$ & $17.1 \%$ \\
\hline Unknown & 18,149 & 1.0 & 21,328 & 1.0 & 39,477 & $0.6 \%$ \\
\hline \multicolumn{7}{|l|}{ Race/Ethnicity (count, \%) } \\
\hline White & 622,729 & 24.0 & 781,387 & 21.0 & $1,404,116$ & $22.3 \%$ \\
\hline Black & 97,593 & 4.0 & 60,987 & 2.0 & 158,580 & $2.5 \%$ \\
\hline Hispanic & 13,444 & 1.0 & 27,060 & 1.0 & 40,504 & $0.6 \%$ \\
\hline Other & 27,766 & 1.0 & 64,687 & 2.0 & 92,453 & $1.5 \%$ \\
\hline Unknown & $1,786,120$ & 70.0 & $2,814,197$ & 75.0 & $4,600,317$ & $73.1 \%$ \\
\hline \multicolumn{7}{|l|}{ Population Density (count, \%) } \\
\hline Rural & 296,760 & 12.0 & 659,061 & 18.0 & 955,821 & $15.2 \%$ \\
\hline Suburb & 624,428 & 25.0 & 960,385 & 26.0 & $1,584,813$ & $25.2 \%$ \\
\hline Urban & $1,608,315$ & 63.0 & $2,107,544$ & 56.0 & $3,715,859$ & $59.0 \%$ \\
\hline Unknown & 18,149 & 1.0 & 21,328 & 1.0 & 39,477 & $0.6 \%$ \\
\hline \multicolumn{7}{|l|}{ Household Income (\$) } \\
\hline$\leq \$ 45 \mathrm{~K}$ & $1,656,774$ & $65.0 \%$ & $2,414,518$ & $64.4 \%$ & $4,071,292$ & $64.7 \%$ \\
\hline $45 \mathrm{~K}$ and $\$ 87.5 \mathrm{~K}$ & 434,298 & $17.0 \%$ & 560,368 & $14.9 \%$ & 994,666 & $15.8 \%$ \\
\hline$\$ 87.5$ and $\$ 112 \mathrm{~K}$ & 219,535 & $8.6 \%$ & 320,330 & $8.5 \%$ & 539,865 & $8.6 \%$ \\
\hline$\geq \$ 112 \mathrm{~K}$ & 237,045 & $9.3 \%$ & 453,102 & $12.1 \%$ & 690,147 & $11.0 \%$ \\
\hline Attained Education & 8,531 & $0.3 \%$ & 17,652 & $0.5 \%$ & 26,183 & $0.4 \%$ \\
\hline HS diploma & 976,142 & $38.3 \%$ & $1,112,675$ & $29.7 \%$ & $2,088,817$ & $33.2 \%$ \\
\hline Any college & $1,283,238$ & $50.4 \%$ & $2,015,512$ & $53.8 \%$ & $3,298,750$ & $52.4 \%$ \\
\hline Unknown & 279,741 & $11.0 \%$ & 602,479 & $16.1 \%$ & 882,220 & $14.0 \%$ \\
\hline RxRiskV (mean, SD) & 5.10 & 2.86 & 5.02 & 2.95 & 5.05 & 2.92 \\
\hline
\end{tabular}


Table 2. Utilization of HZ Vaccine in Eligible Adults by Coverage Type. OOP: out of pocket.

\begin{tabular}{|c|c|c|c|c|c|c|}
\hline \multirow{3}{*}{ Eligible Members 2007-2014 (Count) } & \multirow{2}{*}{\multicolumn{2}{|c|}{$\begin{array}{c}\text { Medicare MAPD } \\
2,547,652\end{array}$}} & \multirow{2}{*}{\multicolumn{2}{|c|}{$\begin{array}{c}\text { Medicare Pt D } \\
3,748,318 \\
\end{array}$}} & \multirow{2}{*}{\multicolumn{2}{|c|}{$\begin{array}{c}\text { All } \\
6,295,970\end{array}$}} \\
\hline & & & & & & \\
\hline & $N$, or Means & $\%$, or SD & $N$, or Means & $\%$, or SD & $N$, or Means & $\%$, or SD \\
\hline \multicolumn{7}{|l|}{ Overall abandonment $(\mathrm{N}$, rate $\%)$} \\
\hline Fulfilled & 175,506 & & 334,628 & & 510,561 & \\
\hline Abandoned & 17,100 & 8.9 & 22,995 & 6.4 & 40,139 & 7.3 \\
\hline \multicolumn{7}{|l|}{ eRx abandoned $(\mathrm{N}$, rate $\%)$} \\
\hline Fulfilled & 20,242 & & 32,763 & & 53,005 & \\
\hline Abandoned & 8,160 & 28.7 & 9,312 & 22.1 & 17,472 & 24.8 \\
\hline \multicolumn{7}{|l|}{ Trad. abandoned $(\mathrm{N}$, rate $\%)$} \\
\hline Fulfilled & 153,308 & & 296,492 & & 449,800 & \\
\hline Abandoned & 8,742 & 5.4 & 13,103 & 4.2 & 21,845 & 4.6 \\
\hline OOP among fulfilled ( $\$$, mean, SD) & 71.35 & 40.95 & 84.83 & 52.17 & 80.21 & 49.03 \\
\hline OOP among abandoned ( $\$$, mean, SD) & 79.76 & 45.51 & 94.52 & 61.08 & 88.24 & 55.45 \\
\hline Total OOP $(\$$, mean in 12 months, SD) & 419.9 & 661.87 & 577.94 & 866.09 & 515.25 & 795.15 \\
\hline
\end{tabular}

Table 3. Logistic Regression on Abandonment of HZ Vaccine among MAPD and prescription drug plans (PDP) Members.

\begin{tabular}{|c|c|c|c|c|}
\hline Effect & Odds Ratio & & 95\% Confidence Limits & $P$ Value \\
\hline Female (ref: male) & 0.96 & 0.94 & 0.99 & 0.001 \\
\hline Age & 1.01 & 1.01 & 1.01 & $<0.001$ \\
\hline \multicolumn{5}{|l|}{ Race (ref: White) } \\
\hline Black & 1.58 & 1.47 & 1.69 & $<0.001$ \\
\hline Hispanic & 1.48 & 1.40 & 1.57 & $<0.001$ \\
\hline Other race & 0.97 & 0.95 & 1.00 & 0.053 \\
\hline \multicolumn{5}{|l|}{ OOP cost category (ref: $\$ 0-80$ ) } \\
\hline OOP cost category $(>\$ 80$ and $<\$ 90)$ & 1.21 & 1.16 & 1.27 & $<0.001$ \\
\hline OOP cost category $(\geq \$ 90)$ & 1.90 & 1.85 & 1.96 & $<0.001$ \\
\hline \multicolumn{5}{|l|}{ Service Year (ref: 2007) } \\
\hline 2008 & 1.18 & 1.11 & 1.27 & $<0.001$ \\
\hline 2009 & 1.60 & 1.50 & 1.70 & $<0.001$ \\
\hline 2010 & 1.51 & 1.40 & 1.62 & $<0.001$ \\
\hline 2011 & 1.17 & 1.10 & 1.25 & $<0.001$ \\
\hline 2012 & 1.41 & 1.33 & 1.50 & $<0.001$ \\
\hline 2013 & 1.37 & 1.29 & 1.45 & $<0.001$ \\
\hline 2014 & 2.20 & 2.07 & 2.34 & $<0.001$ \\
\hline PDP (ref: MAPD) & 0.84 & 0.82 & 0.86 & $<0.001$ \\
\hline \multicolumn{5}{|l|}{ Geographic area (ref: Northeast) } \\
\hline Midwest & 0.89 & 0.85 & 0.93 & $<0.001$ \\
\hline South & 1.40 & 1.34 & 1.47 & $<0.001$ \\
\hline West & 0.96 & 0.91 & 1.01 & 0.103 \\
\hline \multicolumn{5}{|l|}{ Community type (ref: Suburban) } \\
\hline Urban & 1.20 & 1.17 & 1.23 & $<0.001$ \\
\hline Rural & 0.92 & 0.88 & 0.95 & $<0.001$ \\
\hline \multicolumn{5}{|l|}{ Education (ref: Any college) } \\
\hline Below high school & 1.33 & 1.29 & 1.37 & $<0.001$ \\
\hline High school & 1.16 & 1.12 & 1.20 & $<0.001$ \\
\hline \multicolumn{5}{|l|}{ Household income (ref: High income) } \\
\hline Low income $(<\$ 45,000)$ & 1.48 & 1.25 & 1.75 & $<0.001$ \\
\hline Mid income $(\$ 45,000-87,000)$ & 1.23 & 1.20 & 1.26 & $<0.001$ \\
\hline \multicolumn{5}{|l|}{ Disease Burden } \\
\hline RxRiskV index & 1.07 & 1.06 & 1.07 & $<0.001$ \\
\hline
\end{tabular}

Notes: Outcome: abandoned $=1$ vs. fulfilled $=0$ (vaccinated). Observations: 499,491 (36,550 abandoned, 462,941 fulfilled). 


\section{Discussion}

These study results suggest the importance of certain socioeconomic and demographic factors linked to the likelihood that individuals will be vaccinated when the HZ vaccine is prescribed, recommended, or sought out. These results also mirror those found in studies of HZ vaccination, and other vaccines in which non-white, less affluent, and less highly educated people reported lower vaccination rates than other socioeconomic and demographic groups [19]. Hechter, et al. (2013) [20] reported similar patterns of disparity in a study of eligible health plan members and utilization of the $\mathrm{HZ}$ vaccine. Although they did not specifically examine the impact of member OOP amount related to the vaccine abandonment, they suggested the importance of cost to the patient as a factor related to vaccine utilization [20].

Furthermore, other studies have shown that vaccine abandonment is associated with: (a) financial barriers (e.g., cost-sharing and inadequate reimbursement) [14,21,22]; (b) financial barriers to pharmacies to stock a wide range of recommended vaccines [14]; and (c) insurance benefit design related to coverage of immunizations $[23,24]$. Interventions that reduce patient cost-sharing have reported a broad range of increases in immunizations (1-47\%), with the enhanced vaccination rates dependent on the magnitude of the cost-sharing reduction $[25,26]$.

Similarly, the present study results also support the notion that member OOP cost is significantly associated with vaccine compliance. As the amount of OOP cost increased, vaccine abandonment was more likely. For most people in the analysis, the copayment for the vaccine fell between \$80-90. Utilization rates above and below these levels exhibited the expected pattern; the lower OOP group had a lower probability of abandoning the vaccine, the higher OOP group reported a higher probability of abandonment. In studies of non-adherence focusing on specialty medications, OOP cost was a significant factor in poor adherence and primary abandonment, which may be a factor in this study [27].

Comparing Medicare coverage types also produced interesting differences with regard to cost. Most notable was the difference between MAPD and PDP members. There was $16 \%$ lower odds of abandonment for PDP members than MAPD members.

The limitations in this study included the use of pharmacy data that contained both electronically transmitted and traditionally ordered vaccines. The traditional transmission of orders did not account for members who received the order but never pursued the vaccine. As a result, abandonment rates for traditionally-transmitted orders may be underestimated. Though not as likely to be offered to patients in as many and varied places as other vaccines such as flu, the possibility exists that a patient may have been vaccinated outside of their primary insurance program or may have been vaccinated prior to enrolling, or after leaving the health plan, which may have affected the estimates. Despite efforts to identify $\mathrm{HZ}$ vaccine use prior to the index date, it is possible that individuals with no recorded claim for the vaccine in the study data may have received it under prior coverage.

The limitations that are common to studies using administrative claims data applied to this study also. These included a lack of certain information in the database and errors in claims coding. No causal inference may be ascertained from this study, as it was an observational study using retrospective claims data. Since this study used data from Humana members only, the results may not be generalized to the general population; however, Humana is a large national health plan with members residing in a broad array of geographic regions.

\section{Conclusions}

The results related to socioeconomic and demographic factors indicated that disparities based on income, education, and race/ethnicity regarding vaccine access and abandonment exist. Patient OOP cost was also an important factor influencing $\mathrm{HZ}$ vaccine adoption in individuals enrolled in Medicare. Increased OOP amounts are associated with an increased risk of abandonment. Cost-sharing continues to be an issue for vaccines covered under Medicare Part D, including the HZ vaccine. Programs that improve access to and distribution of the vaccine to a broader segment of the population at risk may improve vaccination rates, minimize disparities, and enhance patient-centered outcomes. Efforts 
to reduce OOP cost of the $\mathrm{HZ}$ vaccine, such as formulary calibration, copay adjustment or patient subsidies, may also help improve use and adherence of $\mathrm{HZ}$ vaccine.

Author Contributions: Conceptualization: all authors; Methodology: all authors; Formal analysis: Z.T., Y.L. and S.S.; Writing — Original Draft Preparation: S.S., Y.L. and Z.T.; Writing—Review \& Editing: all authors.

Funding: This research was funded by Merck and Co., Inc.

Acknowledgments: Mary Costantino, for her editorial assistance.

Conflicts of Interest: Zhuliang Tao, Yong Li, and Stephen Stemkowski are paid employees of Comprehensive Health Insights (CHI), which received funding from Merck to conduct the study reported here. Kelly Johnson, Dongmu Zhang, and Camilo Acosta are paid employees of Merck and Co., Inc. A. Mark Fendrick discloses the following affiliations: Consultant: AbbVie, FMS Inc., Geisinger Health Plan, Janssen, Lilly, MedZed, Merck, Risalto, Sanofi, Sempre Health, Takeda, TriZetto, Wellth, Zansors. Research: AHRQ, CalPERS, Gary and Mary West Health Policy Center, Laura \& John Arnold Foundation, National Pharmaceutical Council, PCORI, PhRMA, RWJ Foundation, State of Michigan/CMS, State of New York. Outside Position: AJMC (Co-editor), MEDCAC member, V-BID Health, LLC (Partner).

\section{References}

1. Burgoon, C.F., Jr.; Burgoon, J.S.; Baldridge, G.D. The natural history of herpes zoster. J. Am. Med. Assoc. 1957, 164, 265-269. [CrossRef]

2. Harding, S.P.; Lipton, J.R.; Wells, J.C. Natural history of herpes zoster ophthalmicus: Predictors of postherpetic neuralgia and ocular involvement. Br. J. Ophthalmol. 1987, 71, 353-358. [CrossRef] [PubMed]

3. Hope-Simpson, R.E. The nature of herpes zoster: A long-term study and a new hypothesis. Proc. R Soc. Med. 1965, 58, 9-20. [PubMed]

4. Lydick, E.; Epstein, R.S.; Himmelberger, D.; White, C.J. Herpes zoster and quality of life: A self-limited disease with severe impact. Neurology 1995, 45, S52-S53. [CrossRef] [PubMed]

5. McGregor, R.M. Herpes zoster, chicken-pox, and cancer in general practice. Br. Med. J. 1957, 1, 84-87. [CrossRef] [PubMed]

6. Oxman, M.; Alani, R. Varicella and herpes zoster. In Fitzpatrick's Dermatology in General Medicine, 4th ed.; McGraw-Hill: New York, NY, USA, 1993; pp. 2543-2572.

7. Ragozzino, M.W.; Melton, L.J.M., 3rd; Kurland, L.T.; Chu, C.P.; Perry, H.O. Population-based study of herpes zoster and its sequelae. Medicine 1982, 61, 310-316. [CrossRef] [PubMed]

8. Straus, S.E.; Reinhold, W.; Smith, H.A.; Ruyechan, W.T.; Henderson, D.K.; Blaese, R.M.; Hay, J. Endonuclease analysis of viral DNA from varicella and subsequent zoster infections in the same patient. N Engl. J. Med. 1984, 311, 1362-1364. [CrossRef] [PubMed]

9. Johnson, B.H.; Palmer, L.; Gatwood, J.; Lenhart, G.; Kawai, K.; Acosta, C.J. Annual incidence rates of herpes zoster among an immunocompetent population in the United States. BMC Infect. Dis. 2015, 15, 502-506. [CrossRef] [PubMed]

10. World Health Organization. The Importance of Pharmacovigilance: Safety Monitoring of Medicinal Products. 2002. Available online: http://apps.who.int/medicinedocs/en/d/Js4893e/ (accessed on 19 November 2018).

11. Food and Drug Administration. Guidance for Industry: Good Pharmacovigilance Practices and Pharmacoepidemiology Assessment. Rockville, MD, March 2005. Available online: https:/ /www.fda.gov/ downloads/Drugs/GuidanceComplianceRegulatoryInformation/Guidances/UCM071696.pdf (accessed on 19 November 2018).

12. Canadian Pain Society Study Day participants. Safety and effectiveness of the herpes zoster vaccine to prevent postherpetic neuralgia: 2014 Update and consensus statement from the Canadian Pain Society. Pain Res. Manag. 2015, 20, 46-47. [CrossRef]

13. Drolet, M.; Oxman, M.N.; Levin, M.J.; Schmader, K.E.; Johnson, R.W.; Patrick, D.; Mansi, J.A.; Brisson, M. Vaccination against herpes zoster in developed countries: State of the evidence. Hum. Vaccin. Immunother. 2013, 9, 1177-1184. [CrossRef] [PubMed]

14. Oxman, M.N.; Levin, M.J.; Johnson, G.R.; Schmader, K.; Straus, S.E.; Gelb, L.D.; Arbeit, R.D.; Simberkoff, M.S.; Gershon, A.A.; Davis, L.E.; et al. A vaccine to prevent herpes zoster and postherpetic neuralgia in older adults. N Engl. J. Med. 2005, 352, 271-284. [CrossRef] [PubMed] 
15. Harpaz, R.; Ortega-Sanchez, I.R.; Seward, J.F. Prevention of Herpes Zoster: Recommendations of the Advisory Committee on Immunization Practices (ACIP). MMWR Morb. Mortal. Wkly. Rep. 2008, 57, 1-30.

16. Williams, W.W.; Lu, P.J.; O’Halloran, A.; Bridges, C.B.; Kim, D.K.; Pilishvili, T.; Hales, C.M.; Markowitz, L.E. Vaccination coverage among adults, excluding influenza vaccination-United States, 2013. MMWR Morb. Mortal. Wkly. Rep. 2015, 64, 95-102. [PubMed]

17. Hurley, L.P.; Lindley, M.C.; Harpaz, R.; Stokley, S.; Daley, M.F.; Crane, L.A.; Dong, F.; Beaty, B.L.; Tan, L.; Babbel, C.; et al. Barriers to the use of herpes zoster vaccine. Ann. Intern. Med. 2010, 152, 555-560. [CrossRef] [PubMed]

18. Sloan, K.L.; Sales, A.E.; Liu, C.F.; Fishman, P.; Nichol, P.; Suzuki, N.T.; Sharp, N.D. Construction and characteristics of the RxRisk-V: A VA-adapted pharmacy-based case-mix instrument. Med. Care 2003, 41, 761-774. [CrossRef] [PubMed]

19. Annunziata, K.; Rak, A.; Del Buono, H.; DiBonaventura, M.; Krishnarajah, G. Vaccination rates among the general adult population and high-risk groups in the United States. PLoS ONE 2012, 7, e50553. [CrossRef] [PubMed]

20. Hechter, R.C.; Tartof, S.Y.; Jacobsen, S.J.; Smith, N.; Tseng, H.F. Trends and disparity in zoster vaccine uptake in a managed care population. Vaccine 2013, 31, 4564-4568. [CrossRef] [PubMed]

21. Hurley, L.P.; Bridges, C.B.; Harpaz, R.; Allison, M.A.; O’Leary, S.T.; Crane, L.A.; Brtnikova, M.; Stokley, S.; Beaty, B.L.; Jimenez-Zambrano, A.; et al. U.S. physicians' perspective of adult vaccine delivery. Ann. Intern. Med. 2014, 160. [CrossRef] [PubMed]

22. Penfold, R.B.; Rusinak, D.; Lieu, T.A.; Shefer, A.; Messonnier, M.; Lee, G.M. Financing and systems barriers to seasonal influenza vaccine delivery in community settings. Vaccine 2011, 29, 9632-9639. [CrossRef] [PubMed]

23. Singer, D.; Davis, M.; Gebremariam, A.; Clark, S. Underinsurance for Recently Recommended Vaccines in Private Health Plans. J. Community Health 2012, 37, 1164-1167. [CrossRef] [PubMed]

24. Pourat, N.; Jones, J.M. Role of Insurance, Income, and Affordability in Human Papillomavirus Vaccination. Am. Manag. Care 2012, 18, 320-330.

25. Briss, P.A.; Rodewald, L.E.; Hinman, A.R.; Shefer, A.M.; Strikas, R.A.; Bernier, R.R.; Carande-Kulis, V.G.; Yusuf, H.R.; Ndiaye, S.M.; Williams, S.M. Reviews of evidence regarding interventions to improve vaccination coverage in children, adolescents, and adults. The Task Force on Community Preventive Services. Am. J. Prev. Med. 2000, 18, 97-140. [CrossRef]

26. Shen, A.K.; O'Grady, M.J.; McDevitt, R.D.; Pickreign, J.D.; Laudenberger, L.K.; Esber, A.; Shortridge, E.F. How might immunization rates change if cost sharing is eliminated? Public Health Rep. 2014, 129, 39-46. [CrossRef] [PubMed]

27. Doshi, J.A.; Li, P.; Ladage, V.P.; Pettit, A.R.; Taylor, E.A. Impact of cost sharing on specialty drug utilization and outcomes: a review of the evidence and future directions. Am. J. Manag. Care 2016, 22, 188-197. [CrossRef] [PubMed]

(C) 2018 by the authors. Licensee MDPI, Basel, Switzerland. This article is an open access article distributed under the terms and conditions of the Creative Commons Attribution (CC BY) license (http://creativecommons.org/licenses/by/4.0/). 